\title{
Communication, Cognition and Competency Development in Healthcare - A model for integrating cognitive ethnography and communication skills training in clinical interventions
}

Daria M. Schwalbe ( $\square$ dschwalbe@sdu.dk)

University of Southern Denmark

Connie Timmermann

Center for Research in Patient Communication, Odense University Hospital

Trine A. Gregersen

Center for Research in Patient Communication, Odense University Hospital

\section{Sune V. Steffensen}

University of Southern Denmark

Jette Ammentorp

Center for Research in Patient Communication, Odense University Hospital

\section{Research Article}

Keywords: intervention design, health communication, person-centered care, blended learning, cognitive ethnography, in situ simulation, mixed methods

Posted Date: February 10th, 2022

DOI: https://doi.org/10.21203/rs.3.rs-1328202/v1

License: (c) (i) This work is licensed under a Creative Commons Attribution 4.0 International License.

Read Full License 


\title{
Communication, Cognition and Competency Development in Healthcare - A model for integrating cognitive ethnography and communication skills training in clinical interventions.
}

\author{
Authors: Daria M. Schwalbe ${ }^{1 *}$, Connie Timmermann², Trine A. Gregersen², Sune Vork \\ Steffensen ${ }^{1}$, and Jette Ammentorp ${ }^{2}$ \\ *Corresponding author \\ ${ }^{1}$ Department of Language and Communication, University of Southern Denmark \\ ${ }^{2}$ Center for Research in Patient Communication (CFPK), Odense University Hospital
}

\begin{abstract}
:
Background: This article illustrates how cognitive, organizational, and communicative/interactive processes can be included into the design of micro-skills interventions in healthcare. We present a model for integrating methods of cognitive ethnography and in situ simulation into clinical communication intervention studies to support the implementation process.

Methods: A twelve-week Blended Learning communication training course based on the CalgaryCambridge guide and supported by in situ simulation is conducted among healthcare professionals at an outpatient clinic at a Danish university hospital. Cognitive ethnography is used to document and evaluate implementation and competency development: How learning is absorbed and translated into clinical practice.
\end{abstract}

Results/Discussion: Clinical intervention studies can be designed to include cognitive, organizational, and communicative/interactive processes. The proposed model can effectively support implementation of communicative skills interventions in healthcare. The integration of cognitive ethnography supports documentation of change processes and organizational challenges that arise during the implementation and allows to evaluate whether the intervention is flexible enough to accommodate in "real-time." Integration of cognitive ethnography can also secure necessary and timely adaptability of the program, stimulating the desired change on individual and organizational levels. In situ simulation training provides a further opportunity to train and review communicative skills in the clinic, which may help to better retain the introduced skills, thus promoting sustainable change.

Conclusions: The proposed design can narrow the theory-practice gap, optimize participation and knowledge transfer, and has the potential to generate a positive cultural change, all of which are necessary to improve organizational processes and better patient care. The model works for the benefit of the clinic and may be more suitable for implementation of communication projects than, say, randomized setups. Adopting the integration of cognitive ethnography with clinical

interventions as a way of understanding change processes can ensure adaptable activities and secure quality optimization and change in individual behavior and organizational culture over time.

Improvement of health communication and communicative skills of healthcare providers can create pace for patient-involvement and reduce inequalities, and hence provide better and safer healthcare.

Keywords: intervention design, health communication, person-centered care, blended learning, cognitive ethnography, in situ simulation, mixed methods.

\section{Introduction}

Historically, most studies in healthcare interventions have been hypothesis driven. Therefore, they 
have tried to investigate the impact of interventions by addressing specific and measurable questions in different quantitative study designs, such as case control studies. These methods, although useful, do not capture the complexities of interventions or interventional failures. Cognitive, organizational, and communicative/interactive processes and relational dynamics are important to consider in order to support embodied learning practices that are necessary to secure successful implementation of educational initiatives and desirable behavioral change in organizations. It may also help to avoid implementation failures [1-3]. Existing research on the development of the healthcare professionals' (HCPs') communicative competencies also points to an increasing need for research that allows to investigate and implement elements that can contribute to continuous adaption and maintenance of the intervention and of the acquired skills [4-6]. Well-designed interventions thus require a continuous evaluation and adaptability of activities, as well as a high motivation and participation levels in order for the interventions to be implemented successfully. This brings forth a need for understanding a pragmatic interplay between delivery of research knowledge, HCPs' vision regarding what constitutes good patient-communication (as well as their assessments of their own skills), and their experiences with and responsiveness to interventions, to support the implementation process. In other words, we need to understand how HCPs make meaning of the implemented activities, and at the same time, how these activities (and reasoning) are being embedded in an organizational context, i.e., how they "fit in" into the mundane routines and work life of HCPs.

Nevertheless, most research in implementation of educational programs directed at optimization of non-technical (communicative, cognitive, and relational) skills of HCPs, sees design and implementation of interventions as two distinct processes, treating implementation activities as a series of problem-solving exercises $[4,7,8]$. These studies focus predominantly on the design of facilitatory interventions aimed at implementing change, and/or on measuring whether the designed programs work or not [e.g., 9-11]. They pay little (if any) attention to the actual learning and 
knowledge transference processes, i.e., to how the facilitatory interventions are actually implemented (absorbed and translated) into clinical practice, what strategies are used, what works well, and what are the challenges. Thus, they largely ignore the fact that learning, like problem-solving and clinical reasoning [12], is both an individual (embodied and enacted) process and something embedded in organization, norms, and procedures [13-16].

In contrast, the project 'Communication, Cognition and Competency Development in Healthcare' (3CoD) is designed to investigate the implementation of micro-skills interventions at a Danish university hospital, focusing on knowledge transfer and competence development among Danish HCPs who underwent a systematic competency development training in relation to a key clinical competence: patient-centered communication. The key aim of the project is to investigate (1) how continuous development of communicative and relational skills affects the clinical practice of patient communication, both the actual performance in interaction with patients, and patients' and HCPs' experiences thereof; and (2) in what way in situ simulations and interventions in cognitive processes (problem-solving, decision-making, planning, etc.) contribute to the promotion and development of a functional practice in relation to patient communication.

Following the key questions, the project peruses three key objectives: (1) to develop and implement a generic blended learning concept for the continuous competence development of HCPs' communicative and relational skills; (2) to identify the socio-cognitive processes that can support and maintain patient-centered practice which is desired to be implemented in relation to the actual performance and patient experience thereof; and (3) to develop organizational processes and practices that scaffold implementation during a busy clinical day. Thus, it combines a focus on competence development and patient communication with investigation of socio-cognitive process that affect (positively or negatively) the implementation of organizational initiatives. Following the overall ambition of the project - i.e., to identify the socio-cognitive, interactive, and organizational 
processes that support the development of a patient-centered practice necessary for the establishment of a safer and better-functioning healthcare system — we propose an alternative design. We propose a framework that combines a focus on competency development and patient-attentive, personcentered communication with a broader, ecological investigation of the socio-cognitive and interactive processes that both promote and constrain the implementation of organizational initiatives that support good (appropriate and morally sound) patient communication. The model innovates by merging methods of Cognitive Ethnography (CE) and in situ simulation (ISS) into clinical communication intervention studies to supports the implementation process and secure sustainable change.

In this article, we focus on and describe the design and the methods used in the $3 \mathrm{CoD}$ study to illustrate (1) how clinical intervention studies can be designed to include cognitive, organizational, and communicative/interactive processes; and (2) how researchers and practitioners can work with integrated methods to support the desired change. We argue that the proposed research methodology benefits intervention in at least three significant ways: (1) it helps to understand operational (organizational, communicative, and motivational/psychological) challenges in situ; (2) it secures necessary and timely adaptability of the program, promoting local ownership and higher degree of participation of the learners; and (3) it optimizes implementation and secures change on individual and organizational levels. By focusing on patient-centered communication, the project also has the potential to contribute to an improvement of patient satisfaction and patient safety in hospitals.

\section{Background: Rethinking healthcare research and interventions}

Traditionally, medical science has been dominated by the biomedical, curative approach that focuses on "disease" as a pathological condition (as defined by medical science), rather than "illness" (the culture-specific understanding of disease) [17]. Beginning from the second half of the twentieth 
century, however, a new form of clinical practice stressed the centrality of medical surveillance for understanding health and illness [18], and of risk factors that derived not only from the previous intracorporeal predictors of disease, but also from numerous factors (psychological, social, environmental, etc.) that "exist outside and around the human" ([19], p. 411). This provided conditions for a distinction between illness/disease-centered and person-centered medicine [20,21]. According to Balint, person (or patient)-centered medicine examines the whole person rather than only focusing on the illness [22]. It seeks to understand and treat the patient within their own psychological and social context [23] and is characterized by responsiveness to individual patient differences, more symmetric relation between the patient and the practitioner, shared understanding and more patient involvement [23-25]. On this perspective, having the right communication skills, i.e., skills that enable the HCPs to explore the patient's wishes, views and needs, to be in control and to handle different types of patients [25], becomes the critical skill of the HCPs.

Informed by phenomenological philosophy and the dialogical turn [26] in patient-centered health communication in recent years, studies in person-centered care have placed more attention on reflexive meaning-making accounts as a way of understanding (some aspects of) experiences of individual actors described through linguistic means, often as an alternative to otherwise established quantitative methods. These studies have stressed the centrality of dialogue as an active method to involve and acknowledge patients in health care treatment, and as a more effective approach to treatment than one-way communication from HCPs [27,28], even though they paid little attention to specific care practices and embodied modalities, as urged by recent scholarship on care [e.g, 29-32].

Correspondingly, health care research has seen a growing focus on factors such as the patient's active role and involvement in treatment [33], the patient-therapist relationship [34,35], the patient's attitude to treatment [36,37], and the importance of patients' existential and spiritual needs [38-41]. More recent Danish studies also point to the relational and situational complexity of 
communication, as well as the need to understand and recognize internal barriers that are at play, such as anxiety of showing uncertainty and vulnerability or anxiety to fail [42-44]. Recent years have also seen an increased recognition of the role of the non-technical (cognitive, social/relational, and personal) skills of the HCPs on patient safety, effective delivery of care, and quality in care [45-49]. Several studies have stressed the importance of cognitive (thought) processes, such as decisionmaking and situational awareness, team coordination, and practitioners' capacity to manage stress and fatigue as important resource skills required for safe and effective operations in health care $[42,47,50-52]$. Whereas others point towards a necessity to rethink "communication" and to investigate communication not only as a series of skills, but as a complexity of interactions, authenticity, and creativity, anchored in the relationship between the healthcare professional and the patient [53-56]. This research emphasizes the need for a more holistic approach to patient care, education, training, and organizational measures. The existing gap between clinical research-based knowledge and its implementation into clinical practice [57-59] may in fact reflect the inadequacies of the traditional pathways for the research and implementation, including lack of relevance of the published clinical trials to clinical practice, lack of feedback and incentives for use of evidence-based practices, as well as the lack of adequate infrastructure and systems to support knowledge transference $[8,59,60]$, and/or lack of managerial ability to timely resolve moments of ambiguity or uncertainty which might occur during the implementation [61].

With the increasing focus on person-centered care in recent years, a growing number of interventions focusing on implementation of the HCPs' non-technical (communicative, relational) skills have emerged. The most frequently used interventions aimed at improving patient-centered care are communication training programs on patient-centered communication [6,62-67]. Existing research in communication skills intervention shows a positive effect of communication skills training on HCPs' self-efficacy [11,68-71], and patient outcomes [70,72-75]. It is also evident that 
the most effective training programs are characterized by a "learner"-centered approach and a focus on active practicing of skills over a prolonged period — e.g., by a means of role-play, feedback, and group discussions [76,77].

The crucial component of these programs is that they incorporate activities to promote transfer of the acquired skills into daily practice $[6,78]$. Yet, the research around these programs mainly focuses on measuring the "effectiveness" of intervention by systematic relying on such measurable outcomes as HCPs' self-efficacy and patients' experience of the communication $[6,10,11,79]$. Although valuable, these methods provide little knowledge of the causal factors affecting interventions. Likewise, they are not capable of reflecting the embodied learning and knowledge transfer practice in real-time clinical settings. Yet, questions like, "How and when do HCPs acquire new knowledge?"; "How do they translate and operationalize the acquired knowledge and skills into their daily clinical practices?"; "How does organizational structure and/or local culture of care support or impede learning?"; "What or who motivates them to participate in the activities?"; or "Why do interventions fail in certain contexts?" are vital if we want to secure effective implementation of interventions in clinical setting. It may help to minimize the risk of transfer loss and to nudge and sustain collective motivation [80] and the desired change on individual and organizational levels.

To support the desirable change in organizational culture and to secure that the intervention is flexible enough to accommodate to a real-life clinical work environment, we therefore need research that identifies and assesses contextual factors in relation to clinical interventions aimed at optimizing the non-technical skills of HCPs [81]. We also need a method that allows us to take the complexity of human interaction into account, including cognitive, relational, and organizational factors, as well as processes that affect knowledge transference, motivation, participation, and (consequently) learning of HCPs, as they are exposed to the intervention. The following section 
demonstrates how these issues can be addressed in healthcare by presenting a new approach to intervention studies introduced at Odense University Hospital and exemplified with this project.

\section{Designing and implementing micro-skills interventions in support of person-centered care}

The Communication, Cognition and Competence Development in Healthcare (3CoD) project focuses on development and implementation of intervention which targets the training of a central clinical competence: patient-centered communication. The overall goal of the intervention is to train the communicative and relational skills of HCPs to generate cohesive and efficient organizational behavior that supports person-centered patient care and an equal interprofessional collaboration between the nurse and the doctor with and around the patient. To meet this goal, the study is designed as a three-step intervention study, directed at competency development of person-centered patient care: (1) training based on Feedback Informed Person-centered Communication (FIPeC) is targeted toward generic communicative competences; (2) simulation training is targeted (inter)professional team coordination; and (3) cognitive interventions are targeted to maintain the changes achieved in a robust clinical practice. Concurrently, the intervention is documented through cognitive ethnography (see Figure 1).

\section{Figure 1:}

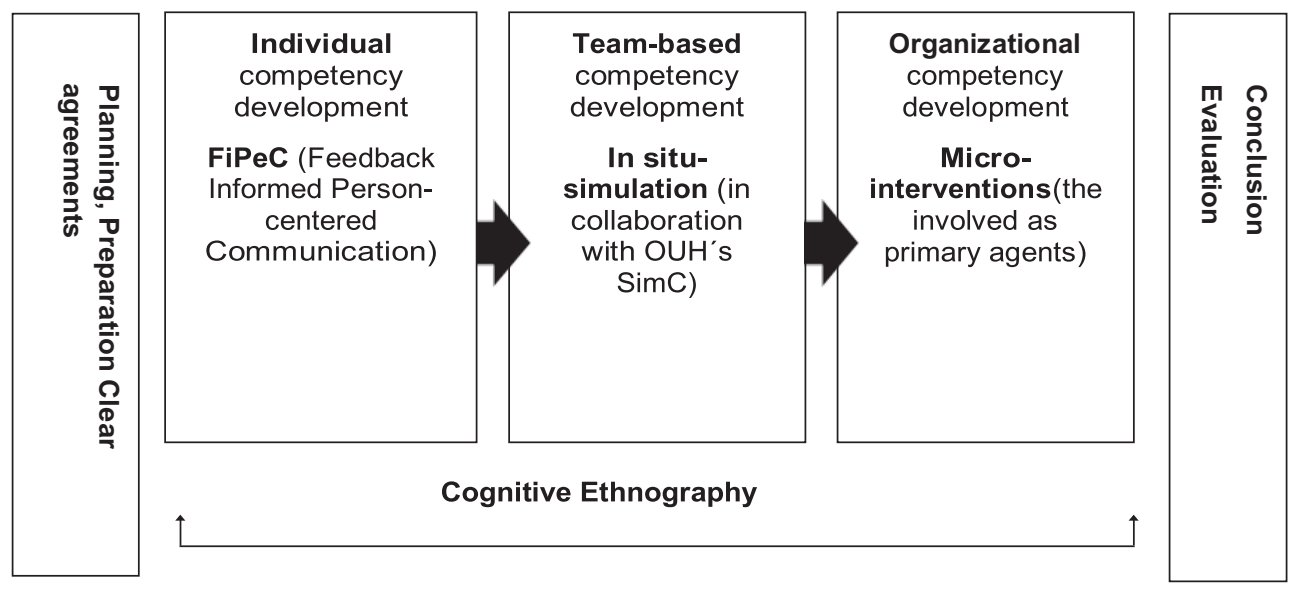




\subsection{Methods}

Acknowledging that effective public health care requires methodological pluralism [77], the project is designed so that there is a close interplay between research methods derived from humanistic interaction research, cognitive ethnography, cognitive science process research, and health science communication and implementation research. During the first phase of the project period, the focus is on development and implementation of The Feedback Informed Person-centered Communication (FIPeC) program, and on ethnographic observation as a way of understanding everyday clinical practices of the HCPs at an outpatient clinic, and the organizational framework within which these practices are situated. In the second phase of the project, to further team-based competency development, this knowledge is used to support the development of simulation scenarios and microinterventions (smaller-scale interventions in the daily activities, where the researchers in collaboration with the clinicians adjust processes and systems). Concurrently, the project uses cognitive ethnography (CE) and systematic video recordings of patient consultations to map how the introduced communication skills affect communication with patients and document the ongoing change (and challenges) at individual and organizational levels, and to evaluate whether the intervention is flexible enough to accommodate in a "real-time" clinical environment. Integration of the systematic effort is directed at improving the non-technical competencies of healthcare professionals that can be sustained and embedded across the whole organization. The Communication Assessment Tool (CAT) is used to measure patient satisfaction and to integrate patient perspective into the research, and together with ethnographic investigation, it functions to further in-depth interpretation of complex dynamics of intervention and learning in healthcare [25]. To connect the learning process to the learners' everyday lives and experiences and to minimize the risk of transfer losses, the study is embedded in a clinical environment. It is carried out at, and in collaboration with, an outpatient clinic at Odense University Hospital (OUH) over a period of 27 months (December 
2019 - February 2022), during which the healthcare professionals at the outpatient clinic (doctors, nurses, and secretaries) participate in a ten-week competency development program.

The setting:

The outpatient clinic is responsible for diagnosis and treatment of both acute and chronical patients, and is part of a larger unit, with the total number of employees corresponding to 120 full-time positions (as of January 2020). The clinic receives approximately 300 visitors daily. The work at the clinic evolves around patient consultations, which are structured according to a tight time-schedule. Given that the time allotted for patient consultations is very limited, good (appropriate and morally sound) and effective communication with the patients is among the primary tasks of the medical ward. Participants:

Approximately thirty of the Department's employees who have their daily routines at the clinic were included into the study. Participants were divided into teams consisting of 6 to 7 persons. To include and secure collaboration across different professional groups, each team consisted of doctors, nurses, and medical secretaries.

Limitations:

As the COVID-19 pandemic put extra pressure on the outpatient clinic in respect to the available resources, the amount of the participating teams was significantly reduced. Only two teams altogether thirteen HCPs - were able to complete the educational program in the timespan allocated for the $3 \mathrm{CoD}$ project. The CAT questionnaires and ISS training, which are part of the proposed model, were likewise omitted during the implementation process at the clinic. Yet, these are part of the proposed intervention design, to be implemented at OUH as part of the collaboration between the hospital and the University of Southern Denmark (cf. Research Portfolio for Human Factors and Patient Safety, CFPK), and are therefore presented here. 


\subsection{Blended Learning as a method for the FIPeC communication skills education}

The designed Feedback Informed Person-centered Communication (FIPeC) training program consists of two elements: FIPeC Basic and FIPeC Mindful (see Figure 2). It is a Blended Learning version of the three-day communication course conducted at all clinical departments at Lillebaelt Hospital by The Center for Research in Patient Communication [11,25,71]. In Blended Learning, the most suitable methods are combined in a learning process, including in-person teaching, e-learning, practical exercises, and skills training, so that learning is optimized [76,82]. The core part of the FIPeC training program (FIPeC Basic) builds on the Calgary-Cambridge Guide (CCG) [83] and its two major pillars, pervasive throughout the conversation: providing structure and building relation. The five basic tasks that doctors and patients routinely have to accomplish in everyday clinical practice are: 1) initiating the session, 2) gathering information, 3) physical examination, 4) explanation and planning, and 5) closing the session. All of these provide a logical schema for both physician-patient interaction and communication skill education [83,84]. FIPeC Mindful uses more reflective learning methods for communication training. These methods aim at cultivating both the communicative and relational skills of HCPs through the application of reflective and dialogical tools [67,71,85,86]. FIPeC Mindful covers such topics as “existential communication”, “vulnerable encounters", and "particularly challenging conversations". The assumption and key purpose of the implementation of the FIPeC learning program is to eliminate differences in operational culture and to develop a common set of guidelines for person-centered patient communication across professional groups and medical wards. The intervention aims at providing HCPs with uniform communicative skills and a shared set of communicative strategies (and, ideally, a shared language) that can be used to manage communicative events in a systematic way and to address, talk about, and collaborate on patients and patient consultations. 
The FIPeC Blended Learning training consists of e-learning modules, in-class in-person training, individual supervisions based on the participants' own video consultations. It is conducted in small teams ( 2 people per team), and a series of exercises to be conducted in the clinic. The elearning modules are structured around short educational (instructional and simulation) videos, accompanied by reflective exercises. After each e-learning module, the HCPs are given instructions (and exercises) for training the introduced skill(s) in the clinic. The in-class in-person training evolves around role play/skills training exercises, based on the HCPs' own cases from the clinic. The program extends over a period of 12 weeks, and includes the following ten modules:

Pre-Class Basic: Five e-learning modules over 5 weeks

Face-to-Face Basic: Two in-class teaching sessions, each lasting $4 \frac{1}{2}$ hours

After-Class Basic: Three e-learning modules over 2 weeks

Pre-Class Mindful: One e-learning module over 1 week

Face-to-Face Mindful: One in-class teaching session for 2 hours

After-Class Mindful: One e-learning module over 1 week (see Figure 2)

\section{Figure 2:}

FIPeC Basic

FIPeC Mindful

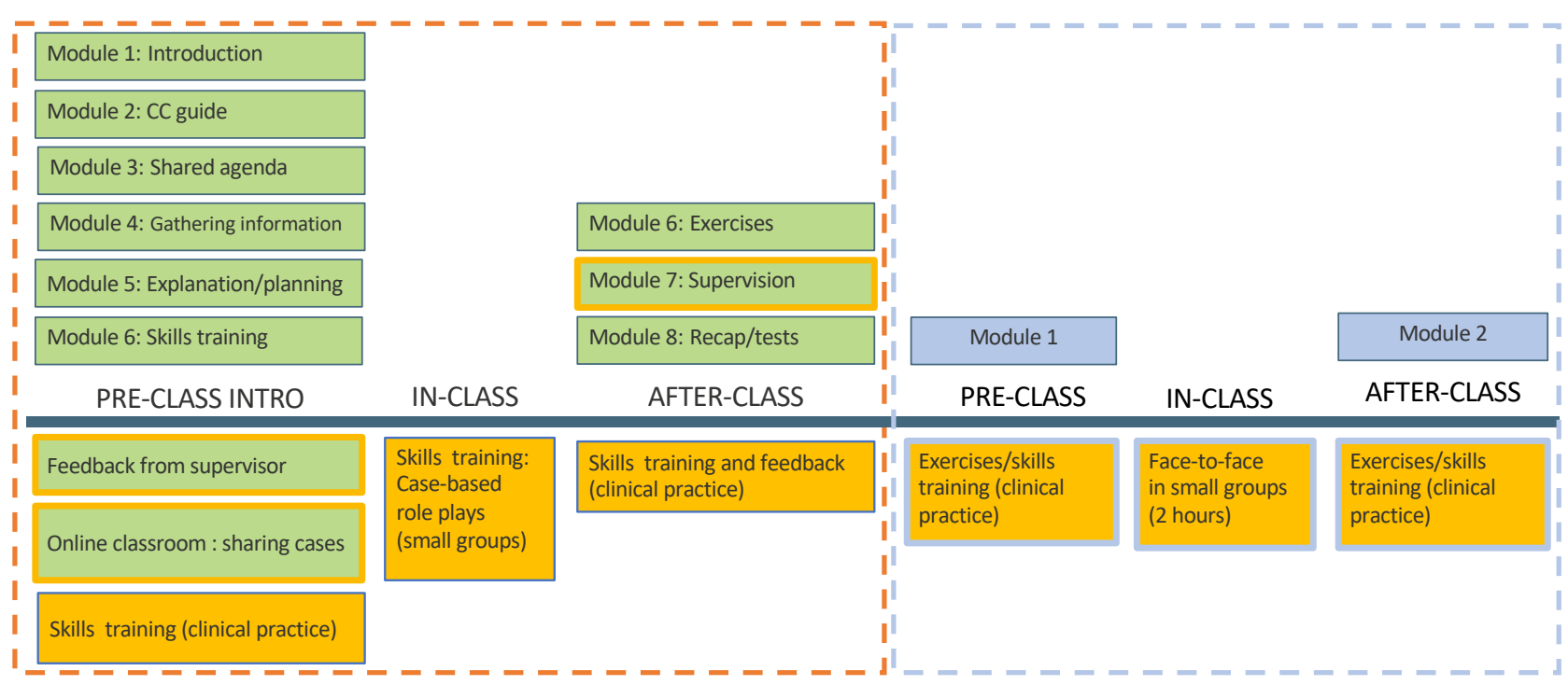




\subsection{Application of in situ simulation for upscaling team-based competence development}

The project uses in situ simulation (ISS) training to support team-based competence development of non-technical skills. ISS training consists of two core elements: the actual training scenario and structured debriefing, and is a team-based training technique performed in the complex clinical practice as a way to support team-based competence development [87-91]. Transfer of learning in technical skills from simulation training into the subsequent clinical practice is well documented $[92,93]$. In healthcare, simulation is increasingly used as a strategy to train both individuals and teams in technical and non-technical skills (e.g., communication, collaboration, and situational awareness) $[52,94-96]$. It is also applied to evaluate organizations and competencies, as well as to identify latent complaints/conditions that predispose errors [97].

As a training method, ISS has a proven effect on training clinical skills. It allows teams to review and strengthen their clinical problem-solving skills in preparation for a crisis or rare serious emergency [97]. Andersen et al. point out that the training of skills on advanced technical simulators develops competencies among the HCPs that allows for patient treatment to begin higher up on the learning curve [98]. This means that the number of typical "beginner's errors" in treating the patient is reduced. ISS has been shown to have a positive effect on HCPs' responses, changes in safety understanding, organizational performance, and teamwork. Mastering skill processes through various forms of simulation training improves doctors/surgeons' and HCPs' performances in, for example, cardiopulmonary resuscitation [99-101].

The theoretical basis for ISS is further supported by intervention system engineering, which suggests that ISS can provide information about both the impeding and promoting factors that influence the five coherent elements of the work environment that affect patient care processes and outcomes: person, tools/technology, tasks, physical environment, and organizational characteristics 
[102-104]. The technique can therefore also be used to test changes, planned infrastructure or interventions [105].

\subsection{Using Cognitive Ethnography (CE) to document and evaluate change process}

Cognitive Ethnography (CE) is a relatively new method that is developed and used specifically to study distributed cognition in organizational contexts [106-108]. It allows to explore how cognitive activity (e.g., learning) is distributed across social and material artefacts as well as over time [109]. "Distributed" means that cognitive processes are seen and examined in relation to the sociocultural context in which they take place, in contrast to classical approaches that focus on mental processes in individuals [110-115]. A key concern in this approach is to examine how the cognitive system is animated through the interactivity of the cognitive agents [116-118]. The strength of this approach (i.e., focus on distributed cognitive system) is that it focuses on how the system contributes to results, rather than having an isolated focus on the individual's capacity and quality/competencies [119].

Methodologically, CE follows the traditional path of ethnography, using such methods as (participant) observations, video observations, interviews, field notes, and other ethnographically informed materials that help to generate an impression of the practice in which cognition takes place; but it focuses on interdependence of cognitive processes (revealed through micro-analysis) and context (revealed through ethnography). It emphasizes observation and analysis of space, objects, concepts, actions, tools, rules, roles, and language as the key features in determining the organization, transfer, and representation of information $[110,120]$. Thus, CE allows us to examine the meaning and conditions of cognitive processes in a particular organizational setting by combining traditional long-term participant observation with the detailed micro-analysis of specific occurrences of events and practices, in which the cognitive aspects of the observed practices are revealed [121]. Because $\mathrm{CE}$ assumes that cognition is distributed through roles, language, relationships and coordinated 
activities, and can be embodied in artifacts and objects, it is also an effective way of studying distributed and embedded activity systems such as games, reading, (communication) models, simulations, and learning [120]. CE is therefore also an apt methodology for the study of learning through interventions. It provides a broader socio-cognitive insight into the structural, interpersonal, and cultural constraints and opportunities for cognitive tasks and processes $[29,122]$.

To evaluate the behavioral change in clinical practice in real time, the project additionally relies on systematic video recordings of patient consultations. We use video recordings to identify and track change in the representations that the HCPs bring into coordination with the patients in the process of ensuring meaningful communication with patients. And we use ethnographic findings to provide evidence for our analytic assessment of interventions concerning how things/materials and events are made relevant to one another in an instance of knowledge transfer [121]. To uncover practitioners' perceptions of cognitive processes in a naturalistic context, in our analysis of the data we draw on Cognitive Task Analysis (CTA) [123,124] and Cognitive Event Analysis (CEA) [125127]. Whereas CTA contributes to the study of what makes certain activities work (or work less well), CEA [125-127], where the researcher works with video recordings of real-time behavior, allows us to assess how this knowledge is enacted in the actual clinical setting [124].

\section{Discussion}

The desired goal of healthcare interventions is a change in behavior and practices on individual and organizational levels that can be sustained over time. Yet, previous studies in communication skills training have shown a decrease in self-efficacy after six months $[9,11,128]$. There is also a considerable variation in how the acquired skills are maintained in different departments, which partly depends on the support of the management and the facilitators' engagement and commitment, and partly on opportunities to work with communication (to try out and test the introduced communicative 
skills) in everyday clinical practice. From organizational studies, we also know that the rate of implementation failures in organizational setting is particularly high, between $60 \%$ and $90 \%$ $[2,3,129]$, and that performance may drop drastically due to the employees' resentment or skepticism towards the strategic change initiative or anxiety about their role, status, or identity within the organization.

Stensaker and colleagues argue that even well-designed interventions may fail, due to (at least in part) the micro-level processes, and in particular, due to "how change recipients make sense of change and shape the change outcome [130-132]." ([133], pp. 162-163). Intervention, they argue, "triggers a series of actions aimed at implementing change" ([133], p. 162). These include translating strategic objectives into operational practices, mediating and negotiating among different organizational levels and groups, developing and evaluating tools for supporting the implementation and monitoring activities, and further planning [133-135]. Goal-oriented social action may, however, result in unanticipated consequences, creating a disjunction between rational choice and outcomes [136]. Moreover, when facing moments of ambiguity or uncertainty, the employees may strive to clarify what is going on by extracting and interpreting cues from their environment and use these cues as a basis for a plausible account that provides order and "makes sense" of what has occurred, and through which they continue to enact in the environment [61]. A successful implementation of interventions, therefore, requires understanding of the micro-level meaning-making processes, and it requires consistent action (and timely adjustments), based on a shared understanding of the changes among healthcare professionals (their assessment of and experiences with both patient communication and implemented skills), to sustain their motivation. It also requires a certain consistency between facilitatory intentions and how these are translated and absorbed into operational level [133]. 
Implementation of clinical interventions takes place in a socio-cultural and organizational context, where procedures, norms, surrounding, interieur, experiences and expectations, affect cognitive processes $[137,138]$, including ways in which HCPs perceive, interpret and make sense of both patient communication and of facilitatory intentions. Evidence derived from experimental studies of learning additionally suggests that learning (being a cognitive function/process) is an embodied activity and affected by multiple factors "spanning cognitive-emotional aspects (fatigue, hunger, lack of motivation) [139], external properties of the study environment (light, sound, ventilation, artefacts) $[140,141]$ and embodied and socio-historical aspects (movement and social and experiential background [142-144]"' (Trasmundi, personal communication 11.06.2020). We therefore need a more systematic knowledge about real-life clinical practices, including how internal (bodily) and external factors effect cognitive and communicative functions and learning, in order to understand how knowledge is absorbed and translated into practice. To understand "learning", we need to understand how "cognitive outcomes link rapid processes to lived experience of action (roughly 'sensemaking'; Weick 1995) and how macro processes are enabled and constrained by ongoing activity" ([146], p. 85).

CE uses systematic observations and video recordings as a method of inquiry, which allows for a micro-level, multimodal analysis of interactions as well as quantitative analysis of the data. It therefore goes beyond the phenomenological approach to healthcare communication, which focuses on the investigation of patients and healthcare providers' subjective experiences of communication, often before and after interventions; hence, making room for the complexity inherent in implementation of interventions and in communication. It opens a possibility to register how the receivers of the interventions perceive and act upon/animate the learning tasks, objectives, and activities, which they are being introduced to; how "learning" and application of newly acquired skills is managed by learners in real-life clinical practice; and how spaciotemporal, sociocultural, and 
situational factors and coordination within the team and/or with the patient influence the learning process. Such knowledge can be used to provide evidence of convergent validity [120,147], opening targeted and methodologically didactic possibilities for changing clinical practices, making it more effective and person-centered.

Within the framework of healthcare communication intervention research in particular, the cognitive-ethnographic approach opens a possibility for investigating cognitive and operational challenges and opportunities that exist in a specific clinical setting in which HCPs solve their respective tasks and where learning is taking place. It allows us to register how the introduced knowledge and skills are embedded (acquired, absorbed, and translated) into clinical practice of the learners, and how people dynamically respond to this situatedness: What are the strategies employed and what are the challenges? It also permits us to scrutinize how situated action (i.e., "necessary ad hoc responses to the actions of others and to the contingencies of particular situations" [148], p. 1), preference formations, and rational choice [136] are related to the broader organizational and sociocultural context. In clinical environments, like in other organizational contexts, the embedded institutional and organizational forces influence the HCPs' cognition (perceptions and reasoning), narrowing their options and shaping their preferences: what individuals consider as rational, useful, appropriate, and/or important at a given moment. These forces provide a profound value-laden field of possible actions [149] and limit the transformative space for learning. For instance, a concern for meeting schedules places a demand on the organization and HCPs in real time that contradicts the major concern of person-centered patient care, namely, a concern for the patient and patient safety (Schwalbe et al., in progress).

The application of ethnographic methods (and on-site ethnographic presence) allows researchers to assess individual/psychological and organizational challenges that incessantly arise in the process (and unforeseen events like, e.g., Covid-19 pandemic). This assessment may help to 
resolve ambiguities that occur during the implementation, to timely adjust and adapt facilitatory interventions and secure participation of the learners in the learning activities. Most crucial, however, is that this method allows us to work in a learning-oriented manner by observing and developing practices on the basis of real, observed issues that practitioners are not immediately phenomenologically aware of in situ [119]. A concrete result based on this method is that the material and practical design of the clinical intervention studies is continuously evaluated and reorganized to create the best conditions for a functional and efficient embedded learning practice. After all, to paraphrase anthropologist Lucy Suchman (1987), if we want to build educational programs for the people, we should watch them using them. With its focus on distributed cognitive systems, CE enables us to do that, revealing factors that may hinder or promote the optimized performance and task-solving (e.g., learning) [119], how people make use of circumstances, language, culture, and objects, to act alone, in dyads and in groups ([150], p. 2).

Whereas CE ensures that human activity (e.g., learning) can be regulated, adapted, and adjusted, "to ensure that collaborative projects (and outcomes) arise as people make sense of tasks, goals and the doings of others (Baber et al. 2006; Pedersen 2012; Perry 2013; but also Weick [and Roberts] 1993" ([151-154]; [146], p. 81), the application of in situ simulation provides a further opportunity to train and review the acquired communicative skills in the clinical setting. It promotes experimental learning by educating HCPs in the actual environment in which the introduced skills are to be applied, which increases both the possibility of achieving success with specific educational goals and a better retention of the acquired skills over time [155]. The solid multidisciplinary foundation of the research design may thus also pave the way for a positive culture change within the organization.

\subsection{Conclusion}


Designing a strategy and implementing that strategy are often treated as two distinct, consecutive processes, but there are many "feedback loops" between making and implementing a strategy that need to be accounted for in order to make the intervention work [156]. Cognitive and organizational processes and relational dynamics are important to consider when designing clinical communication intervention in healthcare in order to support a successful implementation. A unique crossdisciplinary focus on interpersonal and organizational aspects of clinical practice is provided through a research agenda which supports participation and behavioral habit forming in support of personcentered patient care — through the integration of cognitive ethnography and in situ simulation with more traditional healthcare intervention methods. The recommended model allows us to document, address, and eliminate (at least some of the) operational challenges occurring during the intervention, to minimize the risk of interventional failure and transfer loss, and to push and sustain the desired change both on individual and on organizational levels. The proposed design is therefore stronger in order to meet operational challenges occurring during clinical interventions than, for example, the randomized controlled trials, in that it enables a methodologically sound in-depth interpretation of the evidence-based practices and the complex (embedded and embodied) learning dynamics. It allows not only to properly report and evaluate interventions, but also to assess whether proposed interventions are flexible enough to accommodate "in real time". Observational data can be used to optimize interventions, to support the development of scenarios for in situ simulation, and to secure participatory motivation and consistent knowledge transfer by providing timely support to the learners and to the management, in order to resolve moments of ambiguity or uncertainty which might occur during the implementation. By emphasizing the human aspects of treatment — as a counterpoint to the current standardization with electronic medical records, phrases, standardized patient treatment programs, and measurement points (e.g., medicine cards voting) — the proposed 
model has also the potential to generate a positive culture change, an optimized organization and better and more efficient patient care.

\subsection{Implications for practice}

The offered framework creates a unique foundation for similar, clinically accommodated collaborations that may pave the way for the research-based development of the healthcare staff's communicative, relational, and cognitive competencies. It can pave way for how to organize and design environments where decisions have to be made and tasks need to be solved, as well as for optimal training of practitioners in a clinical setting. We also hope that the proposed in this study intervention model will inspire other researchers to combine cognitive ethnography with clinical interventions and in situ simulation training as a way of understanding change processes, to ensure adaptable activities, and to secure quality optimization and change in organizational cultures over time. Initiatives of this kind will further development and implementation of the integrated intervention programs at hospitals.

\section{Ethics approval and consent to practice}

Ethical review and approval from the Legal Service, Research \& Innovation Organisation (RIO) at University of Southern Denmark were acquired for the study in accordance with the local legislation and institutional requirements (reference number: 10.855). Written informed consent was obtained from all participants in the study.

\section{Consent for publication}

Not applicable 


\section{Availability of data and materials}

The data that support the findings of this study are available from the Center for Research in Patient Communication, the University of Southern Denmark, but restrictions apply to the availability of these data, which were used under license for the current study, and so are not publicly available. Data are however available from the authors upon reasonable request and with permission of the University of Southern Denmark.

\section{Competing Interest}

No competing interests. The authors declare that the research was conducted in the absence of any commercial or financial relationships that could be construed as a potential conflict of interest.

\section{Funding}

This project is financed by an internal ("Human Health") research grant from the University of Southern Denmark.

\section{Authors' contributions}

DS developed analytical argument, wrote the paper, and collected the data. JA and SVS designed the study and the study protocol. CT and TG wrote the part on the FIPeC Blended Learning Program and provided the figures. All authors contributed to the article and approved the submitted version.

\section{Acknowledgements}

Not applicable 


\author{
Abbreviations \\ 3CoD - Communication, Cognition and Competency Development \\ CAT - Communication Assessment Tool \\ CCG - Calgary-Cambridge Guide \\ CE - Cognitive Ethnography \\ CEA - Cognitive Event Analysis \\ CFPK - Center for Research in Patient Communication \\ CTA - Cognitive Task Analysis \\ FIPeC - The Feedback Informed Person-centered Communication \\ HCP - Healthcare professionals \\ ISS - in situ simulation \\ OUH - Odense University Hospital \\ SDU - University of Southern Denmark
}

\title{
References
}

1. Beer M, Eisenstat RA. The silent killers of strategy implementation and learning. Sloan Manage Rev. 2000;41(4):29.

2. Higgs M, Rowland D. All changes great and small: Exploring approaches to change and its leadership. J Chang Manag. 2005;5(2):121-51.

3. Kaplan RS, Norton DP. The balanced scorecard: measures that drive performance. Harv Bus Rev. 2005;83(7):172.

4. Glasgow RE, Lichtenstein E, Marcus AC. Why Don't We See More Translation of Health Promotion Research to Practice? Rethinking the Efficacy-to-Effectiveness Transition. Am J public Heal. 2003;93(8):1261-7.

5. Greenhalgh T, Robert G, MacFarlane F, Bate P, Kyriakidou O. Diffusion of Innovations in Service Organizations: Systematic Review and Recommendations. Milbank Q. 2004;82(4):581-629.

6. Ammentorp J, Bigi S, Silverman J, Sator M, Gillen P, Ryan W, et al. Upscaling 
communication skills training - lessons learned from international initiatives. Patient Educ Couns. 2021;104(2):352-9.

7. Greenwald P, Cullen JW. The new emphasis in cancer control. JNCI J Natl Cancer Inst. 1985;74(3):543-51.

8. Ammentorp J, Kofoed PE. Research in communication skills training translated into practice in a large organization: A proactive use of the RE-AIM framework. Patient Educ Couns [Internet]. 2011;82(3):482-7. Available from: http://dx.doi.org/10.1016/j.pec.2011.01.002

9. Ammentorp J, Sabroe S, Kofoed PE, Mainz J. The effect of training in communication skills on medical doctors' and nurses' self-efficacy. A randomized controlled trial. Patient Educ Couns. 2007 Jun;66(3):270-7.

10. Iversen ED, Steinsbekk A, Falbe Vind B, Bangsgaard A, Cold S, Ammentorp J. Translation and cultural adaptation of the Communication Assessment Tool (CAT), developing a Danish and Norwegian version. Int J Qual Heal care. 2019;31(10):748-51.

11. Wolderslund M, Kofoed P-E, Ammentorp J. The effectiveness of a person-centred communication skills training programme for the health care professionals of a large hospital in Denmark. Patient Educ Couns. 2021;104(6):1423-30.

12. Gallagher S, Payne H. The role of embodiment and intersubjectivity in clinical reasoning. Body, Mov Danc Psychother. 2015;10(1):68-78.

13. Gallagher S. Embodied and socially embedded learning/. Gallagher S, editor. Aarhus: Network for Non-Scholastic Learning, NNL; 1999. (Working papers ; No. 10/1999).

14. Illeris K. Workplace learning and learning theory. J Work Learn. 2003;15(4):167-78.

15. Stetsenko A. The transformative mind : expanding Vygotsky's approach to development and education. New York: Cambridge University Press; 2017.

16. Vygotsky LS. Play and Its Role in the Mental Development of the Child. Int Res early Child Educ. 2016;7(2):3.

17. Morris MW, Leung K, Ames D, Lickel B. Views from inside and outside: Integrating Emic and Etic Insights about Culture and. Vol. 24, Source: The Academy of Management Review. 1999.

18. Armstrong D. The rise of surveillance medicine. Sociol Health Illn. 1995;17(3):393-404.

19. Armstrong D. The invention of patient-centred medicine. Soc theory Heal. 2011;9(4):410-8.

20. Joyce D, Marinker M, Balint M, Hunt J. Treatment or Diagnosis. Routledge; 1970.

21. Michael Balint, John Hunt, Dick Joyce, Marshall Marinker. Treatment or Diagnosis. Taylor 
and Francis; 2013.

22. Balint E. The possibilities of patient-centered medicine. J R Coll Gen Pract. 1969;17(82):269-76.

23. Epstein RM, Franks P, Fiscella K, Shields CG, Meldrum SC, Kravitz RL, et al. Measuring patient-centered communication in Patient-Physician consultations: Theoretical and practical issues. Soc Sci Med. 2005;61(7):1516-28.

24. Arnold S Relman. The Institute of Medicine Report on the Quality of Health Care--Crossing the Quality Chasm: A New Health System for the 21st Century. N Engl J Med. 2001;345(9):702.

25. Iversen ED. Communication Skills Training at Lillebaelt Hospital, Denmark Evaluation of " Clear-Cut Communication with Patients " PhD Thesis. 2020;(June).

26. Gillespie A. Review: The Dialogical Turn: Turning the Corner? Theory Psychol. 2010;20(3):461-3.

27. Jørgensen MW. Patient-centred decision-making? Biocitizens between evidence-based medicine and self-determination. Evid policy. 2015;11(3):311-29.

28. Scheffmann-Petersen M. Den dialogiske vending i personcentreret sundhedskommunikation /. Scheffmann-Petersen M, editor. Roskilde: Institut for Kommunikation og Humanistisk Videnskab, Roskilde Universitet; 2016.

29. Bro Pedersen S. The cognitive ecology of human errors in emergency medicine : an interactivity-based approach. 1. oplag. Odense: University of Southern Denmark; 2015.

30. Trasmundi SB. Skilled Embodiment in Emergency Medicine. Chinese Semiot Stud = Zhongguo fu hao xue yan jiu. 2019;15(4):627-51.

31. Trasmundi SB, Philipsen JS. Embodiments and co-actions: The function of trust and reenactment in the practice of psychotherapy. Cogn Semiot. 2020;13(2).

32. Arnold L. Communication as Care across Borders: Forging and Co-Opting Relationships of Obligation in Transnational Salvadoran Families. Am Anthropol. 2021;123(1):137-49.

33. Barrett B, Müller D, Rakel D, Rabago D, Marchand L, Scheder JC. Placebo, Meaning, and Health. Perspect Biol Med. 2006;49(2):178-98.

34. Kelley JM, Kraft-Todd G, Schapira L, Kossowsky J, Riess H. The influence of the patientclinician relationship on healthcare outcomes: a systematic review and meta-analysis of randomized controlled trials. PLoS One. 2014;9(4):e94207-e94207.

35. Rakel D, Barrett B, Zhang Z, Hoeft T, Chewning B, Marchand L, et al. Perception of 
empathy in the therapeutic encounter: Effects on the common cold. Patient Educ Couns. 2011;85(3):390-7.

36. Hyland ME, Geraghty AW., Joy OE., Turner SI. Spirituality predicts outcome independently of expectancy following flower essence self-treatment. J Psychosom Res. 2006;60(1):53-8.

37. Price D, Finnis DG, Benedetti F. A Comprehensive Review of the Placebo Effect : Recent Advances and Current Thought. Annu Rev Psychol. 2008;59(1):565-90.

38. Hvidt NC, Hvidtjørn D, Christensen K, Nielsen JB, Søndergaard J. Faith Moves Mountains-Mountains Move Faith: Two Opposite Epidemiological Forces in Research on Religion and Health. J Relig Health. 2017;56(1):294-304.

39. Hvidt NC, Ammentorp J, Clemensen J, Steenfeldt VØ, Moestrup L, Søndergaard J. Eksistentiel og åndelig omsorg i Danmark. Klin Sygepleje. 2018;32(4):265-80.

40. Hvidt NC, Nielsen KT, Kørup AK, Prinds C, Hansen DG, Viftrup DT, et al. What is spiritual care? Professional perspectives on the concept of spiritual care identified through group concept mapping. BMJ Open. 2020;10(12):e042142-e042142.

41. Baker LR, Martimianakis MA (Tina), Nasirzadeh Y, Northup E, Gold K, Friesen F, et al. Compassionate Care in the Age of Evidence-Based Practice: A Critical Discourse Analysis in the Context of Chronic Pain Care. Acad Med. 2018;93(12):1841-9.

42. Gulbrandsen P, Clayman ML, Beach MC, Han PK, Boss EF, Ofstad EH, et al. Shared decision-making as an existential journey: Aiming for restored autonomous capacity. Patient Educ Couns. 2016;99(9):1505-10.

43. Assing Hvidt E, Søndergaard J, Ammentorp J, Bjerrum L, Gilså Hansen D, Olesen F, et al. The existential dimension in general practice: identifying understandings and experiences of general practitioners in Denmark. Scand J Prim Health Care. 2016;34(4):385-93.

44. Assing Hvidt E, Søndergaard J, Hansen DG, Gulbrandsen P, Ammentorp J, Timmermann C, et al. "We are the barriers": Danish general practitioners' interpretations of why the existential and spiritual dimensions are neglected in patient care. Commun Med. 2017;14(2):108-20.

45. Kohn LT, Corrigan JM, Donaldson MS. To err is human : building a safer health system. Kohn LT, Corrigan JM, Donaldson MS, editors. Washington, D.C: National Academy Press; 2000.

46. Amalberti R. Human Error at the Centre of the Debate on Safety. In: Navigating Safety. Dordrecht: Springer Netherlands; 2013. p. 19-52. (SpringerBriefs in Applied Sciences and 
Technology).

47. Sevdalis N. (PDF) Non-technical skills and the future of teamwork in healthcare settings [Internet]. 2013 [cited 2021 Dec 8]. Available from:

https://www.researchgate.net/publication/264622634_Non-

technical_skills_and_the_future_of_teamwork_in_healthcare_settings

48. Agha RA, Fowler AJ, Sevdalis N. The role of non-technical skills in surgery. Ann Med Surg. 2015;4(4):422-7.

49. Reason J. Understanding adverse events: human factors. Qual Heal Care. 1995;4(2):80-9.

50. Flin R, O'Connor P, Crichton M. Safety at the Sharp End. 1st ed. Farnham: CRC Press; 2008.

51. Hazlehurst B, McMullen CK, Gorman PN. Distributed cognition in the heart room: How situation awareness arises from coordinated communications during cardiac surgery. $\mathrm{J}$ Biomed Inform. 2007;40(5):539-51.

52. Fioratou E, Flin R, Glavin R, Patey R. Beyond monitoring: distributed situation awareness in anaesthesia. Br J Anaesth BJA. 2010;105(1):83-90.

53. Salmon P, Young B. Qualitative methods can test and challenge what we think we know about clinical communication - if they are not too constrained by methodological 'brands.' Patient Educ Couns. 2018;101(9):1515-7.

54. Mitchell AJ, Selmes T. Why don't patients attend their appointments? Maintaining engagement with psychiatric services. Adv Psychiatr Treat R Coll Psychiatr J Contin Prof Dev. 2007;13(6):423-34.

55. Lüchau EC, Grønning A. Collaborative domestication: How patients use and experience video consultations with their general practitioner. MedieKultur J media Commun Res [Internet]. 2022 Jan 4 [cited 2022 Jan 7];37(71):224-44. Available from: https://tidsskrift.dk/mediekultur/article/view/123374

56. Hillen MA, de Haes HCJM, Verdam MGE, Smets EMA. Trust and Perceptions of Physicians' Nonverbal Behavior Among Women with Immigrant Backgrounds. J Immigr Minor Heal. 2018 Aug 1;20(4):963-71.

57. Glasgow RE, Bull SS, Gillette C, Klesges LM, Dzewaltowski DA. Behavior change intervention research in healthcare settings. Am J Prev Med. 2002;23(1):62-9.

58. McGlynn EA, Asch SM, Adams J, Keesey J, Hicks J, DeCristofaro A, et al. The Quality of Health Care Delivered to Adults in the United States. N Engl J Med. 2003;348(26):2635-45. 
59. Tunis SR, Stryer DB, Clancy CM. Practical Clinical Trials: Increasing the Value of Clinical Research for Decision Making in Clinical and Health Policy. JAMA. 2003;290(12):1624-32.

60. Glasgow RE, Magid DJ, Beck A, Ritzwoller D, Estabrooks PA. Practical Clinical Trials for Translating Research to Practice: Design and Measurement Recommendations. Med Care. 2005;43(6):551-7.

61. Maitlis S, Christianson M. Sensemaking in Organizations: Taking Stock and Moving Forward. Acad Manag Ann. 2014;8(1):57-125.

62. Dwamena F, Holmes-Rovner M, Gaulden CM, Jorgenson S, Sadigh G, Sikorskii A, et al. Interventions for providers to promote a patient-centred approach in clinical consultations. Cochrane Libr. 2012;2013(12):CD003267-CD003267.

63. Poitras M-E, Maltais M-E, Bestard-Denommé L, Stewart M, Fortin M. What are the effective elements in patient-centered and multimorbidity care? A scoping review. BMC Health Serv Res. 2018;18(1):446-446.

64. Gregersen TA, Birkelund R, Wolderslund M, Netsey-Afedo ML, Steffensen KD, Ammentorp J. What matters in clinical trial decision-making: a systematic review of interviews exploring cancer patients' experiences. Scand J Caring Sci. 2019;33(2):266-78.

65. Moore PM, Rivera S, Bravo-Soto GA, Olivares C, Lawrie TA, Moore PM. Communication skills training for healthcare professionals working with people who have cancer. Cochrane Libr. 2018;2018(7):CD003751-CD003751.

66. Smith SM, Soubhi H, Fortin M, Hudon C, O’Dowd T. Interventions for improving outcomes in patients with multimorbidity in primary care and community settings. Cochrane database Syst Rev. 2012;(4):CD006560-CD006560.

67. Timmermann C, Prinds C, Ammentorp J, Larsen H. Relationer i Sundhedsvæsenet - hvorfor og hvordan? In: Hvidt EA, Søndergaard J, Grønning A, editors. Relationer i sundhedsvæsenet: hvorfor og hvordan? Samfundslitteraturen; 2021. p. 191-208.

68. Beck RS, Daughtridge R, Sloane PD. Physician-patient communication in the primary care office: a systematic review. J Am Board Fam Pract. 2002;15(1):25-38.

69. Fellowes D, Wilkinson S, Moore P. Communication skills training for health care professionals working with cancer patients, their families and/or carers. Cochrane database Syst Rev. 2004;(2):CD003751-CD003751.

70. Hulsman R., Ros WJ., Winnubst JA., Bensing J. Teaching clinically experienced physicians communication skills. A review of evaluation studies. Med Educ. 1999;33:655. 
71. Ammentorp J, Graugaard LT, Lau ME, Andersen TP, Waidtløw K, Kofoed P-E. Mandatory communication training of all employees with patient contact. Patient Educ Couns. 2014;95(3):429-32.

72. Clark NM, Gong M, Schork MA, Evans D, Roloff D, Hurwitz M, et al. Impact of Education for Physicians on Patient Outcomes. Pediatr. 1998;101(5):831-6.

73. Evans BJ, Stanley RO, Burrows GD. Communication Skills Training and Patients' Satisfaction. Health Commun. 1992;4(2):155-70.

74. Roter DL, Hall JA, Merisca R, Nordstrom B, Cretin D, Svarstad B. Effectiveness of Interventions to Improve Patient Compliance: A Meta-Analysis. Med Care. 1998;36(8):1138-61.

75. Ammentorp J, Kofoed P-E, Laulund LW. Impact of communication skills training on parents perceptions of care: intervention study. J Adv Nurs. Accepted for publ... 2011;67(2):394400.

76. Berkhof M, van Rijssen HJ, Schellart AJ., Anema JR, van der Beek AJ. Effective training strategies for teaching communication skills to physicians: An overview of systematic reviews. Patient Educ Couns. 2011;84(2):152-62.

77. Ammentorp J, Wolderslund M, Timmermann C, Larsen H, Steffensen KD, Nielsen A, et al. How participatory action research changed our view of the challenges of shared decisionmaking training. Patient Educ Couns. 2018 Apr 1;101(4):639-46.

78. Uitterhoeve R., Bensing J., GrolL R., Demulder PH., Van Achterberg T. The effect of communication skills training on patient outcomes in cancer care: a systematic review of the literature. Eur J Cancer Care (Engl). Accepted 1. 2010;19(4):442-57.

79. Iversen ED, Wolderslund MO, Kofoed P-E, Gulbrandsen P, Poulsen H, Cold S, et al. Codebook for rating clinical communication skills based on the Calgary-Cambridge Guide. BMC Med Educ. 2020;20(1):140-140.

80. Dunbar M, Helms SE, Brodell RT. Reducing cognitive errors in dermatology: Can anything be done? J Am Acad Dermatol. 2013;69(5):810-3.

81. Street RL, Makoul G, Arora NK, Epstein RM. How does communication heal? Pathways linking clinician-patient communication to health outcomes. Patient Educ Couns. 2008;74(3):295-301.

82. Stuij SM, Labrie NHM, van Dulmen S, Kersten MJ, Christoph N, Hulsman RL, et al. Developing a digital communication training tool on information-provision in oncology: 
Uncovering learning needs and training preferences. BMC Med Educ. 2018;18(1):220-220.

83. Silverman J, Kurtz S, Draper J. Skills for Communicating with Patients. London: Taylor \& Francis Group; 2013.

84. Ammentorp J. Den gode patientsamtale. 1. udgave. Ammentorp J, editor. Kbh: Munksgaard; 2016.

85. Stelter R. The Art of Dialogue in Coaching. Milton: Taylor and Francis; 2018. (Coaching Psychology).

86. Ammentorp J, Bigi S, Silverman J, Sator M, Gillen P, Ryan W, et al. Upscaling communication skills training - lessons learned from international initiatives. Patient Educ Couns. 2020;

87. McGaghie WC, Issenberg SB, Petrusa ER, Scalese RJ. A critical review of simulation-based medical education research: 2003-2009. Med Educ. Received 16 Febru... 2010;44(1):50-63.

88. McGaghie WC, Issenberg SB, Petrusa ER, Scalese RJ. Effect of practice on standardised learning outcomes in simulation-based medical education. Med Educ. Received 7 June 2... 2006;40(8):792-7.

89. Phillips L, Scheffmann-Petersen M. Minding the Gap Between the Policy and Practice of Patient-Centeredness: Cocreating a Model for Tensional Dialogue in the "Active Patient Support” Program. Qual Health Res. 2020;30(9):1419-30.

90. Peters G. Metadiscourse, materiality and morality in communication skills training with simulated patients. Commun Med [Internet]. 2021 Jan 15 [cited 2021 Dec 8];16(3). Available from: https://journal.equinoxpub.com/CAM/article/view/19089

91. Steinemann S, Berg B, Skinner A, Ditulio A, Anzelon K, Terada K, et al. In situ, multidisciplinary, simulation-based teamwork training improves early trauma care. J Surg Educ. 2011 Nov;68(6):472-7.

92. Schroedl CJ, Corbridge TC, Cohen ER, Fakhran SS, Schimmel D, McGaghie WC, et al. Use of simulation-based education to improve resident learning and patient care in the medical intensive care unit: A randomized trial. J Crit Care. 2012;27(2):219.e7-219.e13.

93. Lois F, Jaffrelot M. In situ simulation. In: Clinical Simulation: Education, Operations and Engineering. Elsevier; 2019. p. 555-67.

94. Rosen MA, Hunt EA, Pronovost PJ, Federowicz MA, Weaver SJ. In situ simulation in continuing education for the health care professions: A systematic review. J Contin Educ Health Prof. 2012;32(4):243-54. 
95. Walker ST, Sevdalis N, McKay A, Lambden S, Gautama S, Aggarwal R, et al. Unannounced in situ simulations: Integrating training and clinical practice. BMJ Qual Saf. 2013 Jun;22(6):453-8.

96. Gjeraa K, Møller TP, Østergaard D. Efficacy of simulation-based trauma team training of non-technical skills. A systematic review. Acta Anaesthesiol Scand. 2014;58(7):775-87.

97. Patterson MD, Geis GL, Falcone RA, LeMaster T, Wears RL. In situ simulation: Detection of safety threats and teamwork training in a high risk emergency department. BMJ Qual Saf. 2013 Jun;22(6):468-77.

98. Andersen SAW, Konge L, Cayé-Thomasen P, Sørensen MS. Learning Curves of Virtual Mastoidectomy in Distributed and Massed Practice. JAMA Otolaryngol Head Neck Surg. 2015;141(10):1-6.

99. Wayne DB, Didwania A, Feinglass J, Fudala MJ, Barsuk JH, McGaghie WC. SimulationBased Education Improves Quality of Care During Cardiac Arrest Team Responses at an Academic Teaching Hospital. Chest. 2008;133(1):56-61.

100. Breckwoldt J, Lingemann C, Wagner P. Resuscitation training for lay persons in first aid courses: Transfer of knowledge, skills and attitude. Anaesthesist. 2016;65(1):22-9.

101. Edelson DP, Litzinger B, Arora V, Walsh D, Kim S, Lauderdale DS, et al. Improving InHospital Cardiac Arrest Process and Outcomes With Performance Debriefing. Arch Intern Med. 2008;168(10):1063-9.

102. Kobayashi L, Parchuri R, Gardiner FG, Paolucci GA, Tomaselli NM, Al-Rasheed RS, et al. Use of in situ simulation and human factors engineering to assess and improve emergency department clinical systems for timely telemetry-based detection of life-threatening arrhythmias. BMJ Qual Saf. 2013;22(1):72-100.

103. Cheng A, Grant V, Auerbach M. Using Simulation to Improve Patient Safety: Dawn of a New Era. JAMA Pediatr. 2015;169(5):419-20.

104. Weinstock PH, Kappus LJ, Garden A, Burns JP. Simulation at the point of care: Reducedcost, in situ training via a mobile cart. Pediatr Crit Care Med. 2009 Mar 1;10(2):176-81.

105. Nickson CP, Petrosoniak A, Barwick S, Brazil V. Translational simulation: from description to action. Adv Simul. 2021;6(1):6-6.

106. Ball LJ, Ormerod TC. Putting ethnography to work: the case for a cognitive ethnography of design. Int J Hum Comput Stud. 2000;53(1):147-68.

107. Goodwin C. Professional Vision. Am Anthropol [Internet]. 1994 Sep [cited 2020 Nov 
2];96(3):606-33. Available from: http://doi.wiley.com/10.1525/aa.1994.96.3.02a00100

108. Hutchins E. Cognitive Ecology. Top Cogn Sci. Received 2 March ... 2010;2(4):705-15.

109. Trasmundi SB. Errors and Interaction. 2020; Available from: https://benjamins.com/catalog/pbns.309

110. Hutchins E. Cognition in the wild. Hutchins E, editor. Cambridge, Mass: MIT; 1995. (A Bradford book.).

111. Hutchins E. The cultural ecosystem of human cognition. Philos Psychol. 2014;27(1):34-49.

112. Hutchins E. Enculturating the Supersized Mind. Philos Stud. 2011;152(3):437-46.

113. Hutchins E. Ecological Cognition and Cognitive Ecology. Proc Hum Factors Ergon Soc Annu Meet. 2000;44(22):566-9.

114. Hutchins E, Johnson CM. Modeling the Emergence of Language as an Embodied Collective Cognitive Activity. Top Cogn Sci. Received 16 July ... 2009;1(3):523-46.

115. Hutchins E. How a cockpit remembers its speeds. Cogn Sci. 1995;19(3):265-88.

116. Vallee-Tourangeau F. Insight, interactivity and materiality. Pragmat Cogn. 2014;22(1):2744.

117. Steffensen SV. Human Interactivity: Problem-Finding, Problem-Solving, and Verbal Patterns in the Wild. In: Cognition Beyond the Brain. Cham: Springer International Publishing; 2017. p. $85-113$.

118. Gahrn-Andersen R, Johannessen CM, Harvey I, Simonsen LM, Trasmundi SBRO. Interactivity : Why, What and How? 2019;

119. Trasmundi SB. Distribueret kognition og distribueret sprog: analyse af kognitive events i en akutmedicinsk social praksis. NyS Nydanske Stud almen Kommun. 2016;1(50):55.

120. Dubbels B. Cognitive Ethnography: A Methodology for Measure and Analysis of Learning for Game Studies. Int J gaming Comput simulations. 2011;3(1):68-78.

121. Alač M, Hutchins E. I see what you are saying: Action as cognition in fMRI brain mapping practice. J Cogn Cult. 2004;4(3-4):629-61.

122. Hazlehurst B, Gorman PN, McMullen CK. Distributed cognition: An alternative model of cognition for medical informatics. Int J Med informatics (Shannon, Ireland). 2007;77(4):226-34.

123. Crandall B, Klein G, Hoffman RR. Working minds : a practitioner's guide to cognitive task analysis /. Crandall B, Klein G (Gary A)., Hoffman RR, editors. Cambridge, Mass: MIT Press; 2006. (A Bradford book.). 
124. Maria Simonsen L, Vork Steffensen S. Hybrid Cognition in medical simulation: Investigating micro-level organisational cognition.

125. Steffensen SV. Human Interactivity: Problem-Solving, Solution-Probing and Verbal Patterns in the Wild. In: Cognition Beyond the Brain. Springer London; 2013. p. 195-221.

126. Steffensen SV. Cognitive probatonics: Towards an ecological psychology of cognitive particulars. New Ideas Psychol. 2016 Aug 1;42:29-38.

127. Steffensen SV, Vallée-Tourangeau F, Vallée-Tourangeau G. Cognitive events in a problemsolving task: A qualitative method for investigating interactivity in the 17 Animals problem. J Cogn Psychol. 2016 Jan 2;28(1):79-105.

128. Nørgaard B, Ammentorp J, Ohm Kyvik K, Kofoed P-E. Communication skills training increases self-efficacy of health care professionals. J Contin Educ Health Prof. 2012;32(2):90-7.

129. Beer M, Nohria N. Cracking the code of change. Harv Bus Rev. 2000;78(3):133-216.

130. Balogun J, Johnson G. Organizational Restructuring and Middle Manager Sensemaking. Acad Manag J. 2004;47(4):523-49.

131. Maitlis S. The Social Processes of Organizational Sensemaking [Internet]. Vol. 48, Source: The Academy of Management Journal. 2005. Available from: https://www.jstor.org/stable/20159639

132. Thomas JB, Clark SM, Gioia DA. Strategic Sensemaking and Organizational Performance: Linkages Among Scanning, Interpretation, Action, and Outcomes. Acad Manag J. 1993;36(2):239-70.

133. Stensaker I, Falkenberg J, Grønhaug K. Implementation activities and organizational sensemaking. J Appl Behav Sci. 2008 Jun;44(2):162-85.

134. Floyd SW, Wooldridge B. Managing Strategic Consensus: The Foundation of Effective Implementation. 1992.

135. Floyd SW, Wooldridge B. Middle Management's Strategic Influence and Organizational Performance. J Manag Stud. 1997;34(3):465-85.

136. Vaughan D. The Challenger launch decision risky technology, culture, and deviance at NASA. Chicago: University of Chicago Press; 1996.

137. Leape LL. Error in Medicine. JAMA. 1994;272(23):1851-7.

138. Trasmundi SB. Errors and Interaction. Amsterdam/Philadelphia: John Benjamins Publishing Company; 2020. (Pragmatics \& Beyond New Series). 
139. Dettweiler U, Becker C, Auestad BH, Simon P, Kirsch P. Stress in School. Some Empirical Hints on the Circadian Cortisol Rhythm of Children in Outdoor and Indoor Classes. Int J Environ Res Public Health. 2017;14(5):475.

140. Stevenson MP, Schilhab T, Bentsen P. Attention Restoration Theory II: a systematic review to clarify attention processes affected by exposure to natural environments. J Toxicol Environ Health B Crit Rev. 2018;21(4):227-68.

141. Mangen A. Digitization, Reading, and the Body. A Multidiscip Approach to Embodiment. 2020 Jul 17;51-5.

142. Schilhab T. Interactional Expertise as Primer of Abstract Thought. In: The Third Wave in Science and Technology Studies. Cham: Springer International Publishing; 2019. p. 283-95.

143. Kokkola L. Envisaging “Our” Nation: Politicized Affects in Minority Language Literature. Child Lit Educ. 2017;50(2):142-59.

144. Fabry RE, Kukkonen K. Reconsidering the mind-wandering reader: Predictive processing, probability designs, and enculturation. Front Psychol [Internet]. 2019 Jan 8 [cited 2021 Dec 9];9(JAN). Available from: /record/2019-03733-001

145. Weick KE. Sensemaking in organizations. Weick KE, editor. Thousand Oaks: Sage; 1995. (Foundations for organizational science.).

146. Secchi D, Cowley SJ. Cognition in Organisations: What it Is and how it Works. Eur Manag Rev. 2021;18(2):79-92.

147. Westen D, Rosenthal R. Construct validity of psychological tests: Fifty years after Cronbach and Meehl (1955) : Improving construct validity : Cronbach, meehl, and neurath's ship. Psychol Assess. 2005;17(4):409-12.

148. Suchman LA (Lucy A. Plans and situated actions : the problem of human-machine communication /. Cambridge: Cambridge University Press; 1987.

149. Gibson JJ. The ecological approach to visual perception /. Boston: Houghton Mifflin; 1979.

150. Cowley SJ, Vallée-Tourangeau édéric. Cognition Beyond the Brain. London: Springer London, Limited; 2013.

151. Baber C, Smith P, Cross J, Hunter J, McMaster R. Crime Scene Investigation as Distributed Cognition. Pragmat Cogn. 2006;14(2):357-85.

152. Pedersen SB. Interactivity in health care: bodies, values and dynamics. Lang Sci. 2012;34(5):532-42.

153. Perry M. Socially Distributed Cognition in Loosely Coupled Systems. In: Cognition Beyond 
the Brain. London: Springer London; 2013. p. 147-69.

154. Weick KE, Roberts KH. Collective Mind in Organizations: Heedful Interrelating on Flight Decks. Adm Sci Q. 1993;38(3):357-81.

155. Henriksen K, Battles JB, Keyes MA, Grady ML. Advances in Patient Safety: New Directions and Alternative Approaches (Vol. 3: Performance and Tools). Agency Healthc Res Qual [Internet]. 2008 [cited 2021 Dec 9];3(08):1-456. Available from: https://www.ncbi.nlm.nih.gov/books/NBK43665/

156. Leonardi PM. Materializing Strategy: The Blurry Line between Strategy Formulation and Strategy Implementation. Br J Manag. 2015 Jan 1;26(S1):S17-21.

\section{Figure Legends}

Figure 1: Overview of $3 \mathrm{CoD}$ Interventions

Figure 2: Overview of the FIPeC Blended Learning program implemented at OUH 